\title{
Polaronic Conductivity in Iron Phosphate Glasses Containing $\mathrm{B}_{2} \mathrm{O}_{3}$
}

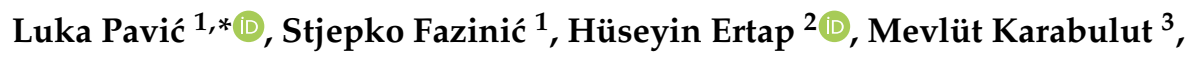 \\ Andrea Moguš-Milanković ${ }^{1}$ and Ana Šantić ${ }^{1, * \mathbb{D}}$ \\ 1 Ruđer Bošković Institute, 10000 Zagreb, Croatia; sfazinic@irb.hr (S.F.); mogus@irb.hr (A.M.-M.) \\ 2 Department of Physics, Kafkas University, 36100 Kars, Turkey; huseyinertap@kafkas.edu.tr \\ 3 Department of Physics, Gebze Technical University, 41400 Gebze, Kocaeli, Turkey; mevlutk@gtu.edu.tr \\ * Correspondence: lpavic@irb.hr (L.P.); asantic@irb.hr (A.Š.)
}

Received: 26 April 2020; Accepted: 26 May 2020; Published: 30 May 2020

\begin{abstract}
We report on the electrical properties of glasses with nominal composition $x \mathrm{~B}_{2} \mathrm{O}_{3}-(100-x)\left[40 \mathrm{Fe}_{2} \mathrm{O}_{3}-60 \mathrm{P}_{2} \mathrm{O}_{5}\right], x=2-20$, mol.\%. The conduction transport in these glasses is polaronic and shows a strong dependence on $\mathrm{Fe}_{2} \mathrm{O}_{3}$ content and polaron number density. The changes in DC conductivity are found not to be directly related to $\mathrm{B}_{2} \mathrm{O}_{3}$, however structural changes induced by its addition impact frequency-dependent conductivity. All glasses obey Summerfield and Sidebottom procedures of scaling conductivity spectra indicating that the polaronic mechanism does not change with temperature. An attempt to produce a super-master curve revealed that shape of the conductivity dispersion is the same for glasses with up to $15.0 \mathrm{~mol} . \% \mathrm{~B}_{2} \mathrm{O}_{3}$ but differs for glass with the highest $\mathrm{B}_{2} \mathrm{O}_{3}$ content. This result could be related to the presence of borate units in the glass network. Moreover, the spatial extent of localized polaron motions increases with the decrease of polaron number density, however, this increase shows a larger slope than for previously reported iron phosphate glasses most probably due to the influence of $\mathrm{B}_{2} \mathrm{O}_{3}$ on glass structure and formation of polarons. While Summerfield scaling procedure fails, Sidebottom scaling yields a super-master curve, which indicates that polaronic hopping lengths also change with changing polaron number density in these glasses.
\end{abstract}

Keywords: iron phosphate glass; polaronic conductivity; glass-former oxide; structure-property relationship; impedance spectroscopy

\section{Introduction}

Iron phosphate-based glasses belong to a family of electronically conducting materials in which the conduction mechanism follows the small polaron hopping theory [1-7]. The polaronic conductivity in these glasses originates from the electron transfer between ferric and ferrous ions and, consequently, shows a strong dependence on the total amount of iron oxide, fraction of ferrous/ferric ions and average distance between them. While literature reports numerous studies on the influence of these parameters on the polaronic conductivity [8-10], as well as the influence of various modifier oxides, mainly transition metal or alkali oxides which themselves are potential active electrical contributors [6,11-18], investigations of the impact of the additional glass-forming oxide on the polaronic transport in iron phosphate glasses are sparse.

In ionically conducting glasses containing a fixed amount of alkali oxide, a gradual substitution of one glass-forming oxide by another produces a pronounced conductivity maximum at the glass composition with the highest fraction of structural units from both glass-forming oxides [19-23]. This effect, called mixed glass-forming effect, has been identified in various combinations of glass-forming oxides, including those based on phosphorous pentoxide and clearly reflects the 
importance of the glass structure in ionic transport. Bearing in mind that the mechanism of polaronic transport is very different in nature to the ionic one, it is unrealistic to expect such a straightforward relationship between polaronic conductivity and changes in the mixed glass-forming network. However, polaronic conductivity of iron phosphate glasses does depend on the local structural surroundings of iron ions and their long-range connectivity in the glass network which is inherently related to the basic features of the glass network.

In this study, we report a detailed analysis of electrical properties of iron phosphate (IP) glasses of the molar composition $40 \mathrm{Fe}_{2} \mathrm{O}_{3}-60 \mathrm{P}_{2} \mathrm{O}_{5}$ doped with boron oxide (IBP glasses). The structural properties of this glass system are relatively well examined [24-26]. It was shown that $\mathrm{B}_{2} \mathrm{O}_{3}$ enters the glass network as $\mathrm{BO}_{4}$ tetrahedral units and increases the chemical and thermal stability of the glass $[24,25]$. Moreover, in our previous study, we showed that the replacement of a small amount of $\mathrm{Fe}_{2} \mathrm{O}_{3}$ by $\mathrm{B}_{2} \mathrm{O}_{3}$ in glasses with fixed phosphate content $(60 \mathrm{~mol} . \%)$ induces local structural disorder which influences polaronic transport giving rise to a deviation from the Summerfield scaling of conductivity spectra [27].

The present work aims to investigate this interesting behavior further and to examine the structural-electrical properties relationship in glasses in which up to $17.7 \mathrm{~mol} . \%$ of $\mathrm{B}_{2} \mathrm{O}_{3}$ is systematically added to $40 \mathrm{Fe}_{2} \mathrm{O}_{3}-60 \mathrm{P}_{2} \mathrm{O}_{5}$ glasses at the expense of both $\mathrm{Fe}_{2} \mathrm{O}_{3}$ and $\mathrm{P}_{2} \mathrm{O}_{5}$. Such variation in composition in which $\mathrm{Fe} / \mathrm{P}$ ratio is kept constant (0.67), involves smaller changes in overall $\mathrm{Fe}_{2} \mathrm{O}_{3}$ amount in comparison to the previously studied system [27], but different structural properties. Indeed, the structural study of both glass systems showed that the addition of $\mathrm{B}_{2} \mathrm{O}_{3}$ with simultaneous decrease of contents of both $\mathrm{Fe}_{2} \mathrm{O}_{3}$ and $\mathrm{P}_{2} \mathrm{O}_{5}$ decreases the thermal stability of glasses, whereas an opposite trend is observed for an exchange of just $\mathrm{Fe}_{2} \mathrm{O}_{3}$ by $\mathrm{B}_{2} \mathrm{O}_{3}$ [24]. Therefore, in this study, we present a detailed analysis of the electrical properties of these glasses in a wide range of temperatures and frequencies in order to address the role of glass structure in the processes of polaronic transport and to determine parameters that govern them.

\section{Materials and Methods}

The batch composition of the glasses selected for this investigation is $x \mathrm{~B}_{2} \mathrm{O}_{3}-(100-x)$ $\left[40 \mathrm{Fe}_{2} \mathrm{O}_{3}-60 \mathrm{P}_{2} \mathrm{O}_{5}\right], x=2-20$, mol.\%. Glasses were prepared by melting homogenous mixtures of reagent grade chemicals $\left(\mathrm{B}_{2} \mathrm{O}_{3}-\mathrm{Fe}_{2} \mathrm{O}_{3}-\mathrm{P}_{2} \mathrm{O}_{5}\right)$ (Sigma Aldrich, Darmstadt, Germany) in appropriate quantities in high-density alumina crucibles at $1150-1200^{\circ} \mathrm{C}$ in the air for $1-2 \mathrm{~h}$. The details of the preparation procedure are given in Ref [24]. Melt is quenched by pouring into a $1 \mathrm{~cm} \times 1 \mathrm{~cm} \times 5 \mathrm{~cm}$ steel mold. The resulting glass bars are then moved quickly to an annealing furnace, annealed at $475^{\circ} \mathrm{C}$ for $3 \mathrm{~h}$ and slowly cooled down to room temperature. The glass samples are designated in accordance with the amount of boron oxide in batch composition. For instance, B- 2 glass contains 2 mol.\% of $\mathrm{B}_{2} \mathrm{O}_{3}$. The powder X-ray diffraction (XRD-6000 diffractometer, Shimadzu, Kyoto, Japan) studies are performed to confirm the amorphous nature of the samples [24]. The exact composition of glass samples was determined by particle induced gamma-ray emission (PIGE) technique [28] using $3 \mathrm{MeV}$ protons from the Ruđer Bošković Institute (RBI) Tandetron accelerator (High Voltage Engineering Europa B.V., Amersfoort, The Netherlands) and high-resolution high purity germanium (HPGe) detector (Canberra Industries, Meriden, CT, USA) to detect gamma rays from the measured samples. Gamma rays of boron (429 and $718 \mathrm{keV})$, phosphorus (1266 keV), iron $(847 \mathrm{keV})$ and oxygen $(871 \mathrm{keV})$ were used for quantitative analysis of spectra and determination of the elemental composition of samples. Proton elastic backscattered spectra (EBS) and collected proton charges were recorded simultaneously to help in the analysis. Details about experimental setup and data analysis procedure can be found elsewhere $[28,29]$.

Before performing electrical/dielectric measurements annealed bars were cut into disks. Thin gold electrodes were sputtered as contacts onto both sides of $1 \mathrm{~mm}$ thick sample disks using sputter coater SC7620 (Quorum Technologies Ltd., Laughton, East Sussex, UK). Electrical and dielectric properties were attained by measuring complex impedance using an impedance analyzer (Novocontrol Alpha-AN dielectric spectrometer, Novocontrol Technologies GmbH \& Co. KG, Montabaur, Germany) over a 
wide frequency and temperature range, from $0.01 \mathrm{~Hz}$ to $1 \mathrm{MHz}$ at temperatures between $303 \mathrm{~K}$ and 523 $\mathrm{K}$. The temperature was controlled to $\pm 0.5 \mathrm{~K}$.

\section{Results and Discussion}

The batch and measured compositions of all IBP glasses are shown in Table 1. It can be seen that compositions match reasonably well, with a clear increasing trend for $\mathrm{B}_{2} \mathrm{O}_{3}$, but slightly fluctuating changes for $\mathrm{Fe}_{2} \mathrm{O}_{3}$ and $\mathrm{P}_{2} \mathrm{O}_{5}$.

Table 1. Nominal batch and measured compositions (in mol.\%) for studied $x \mathrm{~B}_{2} \mathrm{O}_{3}-(100-x)$ $\left[40 \mathrm{Fe}_{2} \mathrm{O}_{3}-60 \mathrm{P}_{2} \mathrm{O}_{5}\right]$ glasses.

\begin{tabular}{|c|c|c|c|c|c|}
\hline Glass & $\begin{array}{c}\text { Batch Composition } \\
(\mathrm{mol} \% \mathrm{\%})\end{array}$ & $\begin{array}{l}\text { Measured Composition a } \\
\text { (mol.\%) }\end{array}$ & $\begin{array}{c}\text { Molar O/P } \\
\text { Ratio }\end{array}$ & $\begin{array}{l}\text { Density } \\
\left(\mathrm{g} \mathrm{cm}^{-3}\right)\end{array}$ & $\begin{array}{c}\mathrm{Fe}^{2+} / \mathrm{Fe}_{\text {tot }} \\
\text { Ratio }\end{array}$ \\
\hline B-2 & $2 \mathrm{~B}_{2} \mathrm{O}_{3}-39.2 \mathrm{Fe}_{2} \mathrm{O}_{3}-58.8 \mathrm{P}_{2} \mathrm{O}_{5}$ & $2.3 \mathrm{~B}_{2} \mathrm{O}_{3}-42.8 \mathrm{Fe}_{2} \mathrm{O}_{3}-54.9 \mathrm{P}_{2} \mathrm{O}_{5}$ & 3.73 & 3.06 & 0.22 \\
\hline B-4 & $4 \mathrm{~B}_{2} \mathrm{O}_{3}-38.4 \mathrm{Fe}_{2} \mathrm{O}_{3}-57.6 \mathrm{P}_{2} \mathrm{O}_{5}$ & $3.9 \mathrm{~B}_{2} \mathrm{O}_{3}-39.4 \mathrm{Fe}_{2} \mathrm{O}_{3}-56.7 \mathrm{P}_{2} \mathrm{O}_{5}$ & 3.65 & 2.97 & $\mathrm{~nm}$ \\
\hline B-6 & $6 \mathrm{~B}_{2} \mathrm{O}_{3}-37.6 \mathrm{Fe}_{2} \mathrm{O}_{3}-56.4 \mathrm{P}_{2} \mathrm{O}_{5}$ & $6.2 \mathrm{~B}_{2} \mathrm{O}_{3}-40.2 \mathrm{Fe}_{2} \mathrm{O}_{3}-53.6 \mathrm{P}_{2} \mathrm{O}_{5}$ & 3.80 & 2.94 & $\mathrm{~nm}$ \\
\hline B-8 & $8 \mathrm{~B}_{2} \mathrm{O}_{3}-36.8 \mathrm{Fe}_{2} \mathrm{O}_{3}-55.2 \mathrm{P}_{2} \mathrm{O}_{5}$ & $7.4 \mathrm{~B}_{2} \mathrm{O}_{3}-37.7 \mathrm{Fe}_{2} \mathrm{O}_{3}-54.9 \mathrm{P}_{2} \mathrm{O}_{5}$ & 3.73 & 2.95 & 0.16 \\
\hline B-10 & $10 \mathrm{~B}_{2} \mathrm{O}_{3}-36.0 \mathrm{Fe}_{2} \mathrm{O}_{3}-54 \mathrm{P}_{2} \mathrm{O}_{5}$ & $8.8 \mathrm{~B}_{2} \mathrm{O}_{3}-36.6 \mathrm{Fe}_{2} \mathrm{O}_{3}-54.6 \mathrm{P}_{2} \mathrm{O}_{5}$ & 3.75 & 2.93 & $\mathrm{~nm}$ \\
\hline B-12 & $12 \mathrm{~B}_{2} \mathrm{O}_{3}-35.2 \mathrm{Fe}_{2} \mathrm{O}_{3}-52.8 \mathrm{P}_{2} \mathrm{O}_{5}$ & $10.6 \mathrm{~B}_{2} \mathrm{O}_{3}-37.4 \mathrm{Fe}_{2} \mathrm{O}_{3}-52.1 \mathrm{P}_{2} \mathrm{O}_{5}$ & 3.88 & 3.01 & $\mathrm{~nm}$ \\
\hline B-14 & $14 \mathrm{~B}_{2} \mathrm{O}_{3}-34.4 \mathrm{Fe}_{2} \mathrm{O}_{3}-51.6 \mathrm{P}_{2} \mathrm{O}_{5}$ & $12.7 \mathrm{~B}_{2} \mathrm{O}_{3}-35.0 \mathrm{Fe}_{2} \mathrm{O}_{3}-52.2 \mathrm{P}_{2} \mathrm{O}_{5}$ & 3.87 & 2.89 & $\mathrm{~nm}$ \\
\hline B-18 & $18 \mathrm{~B}_{2} \mathrm{O}_{3}-32.8 \mathrm{Fe}_{2} \mathrm{O}_{3}-49.2 \mathrm{P}_{2} \mathrm{O}_{5}$ & $15.0 \mathrm{~B}_{2} \mathrm{O}_{3}-33.9 \mathrm{Fe}_{2} \mathrm{O}_{3}-51.1 \mathrm{P}_{2} \mathrm{O}_{5}$ & 3.94 & 2.91 & $\mathrm{~nm}$ \\
\hline B-20 & $20 \mathrm{~B}_{2} \mathrm{O}_{3}-32 \mathrm{Fe}_{2} \mathrm{O}_{3}-48 \mathrm{P}_{2} \mathrm{O}_{5}$ & $17.7 \mathrm{~B}_{2} \mathrm{O}_{3}-32.5 \mathrm{Fe}_{2} \mathrm{O}_{3}-49.8 \mathrm{P}_{2} \mathrm{O}_{5}$ & 4.01 & 2.86 & $\mathrm{~nm}$ \\
\hline
\end{tabular}

For a meaningful analysis of the transport properties of glasses, it is important to consider accurate glass composition especially in the case like this, where the glass composition changes in steps of just a few mol.\%. An exact glass composition along with the density of glasses (also shown in Table 1) enables precise calculation of charge carrier (polaron) number density which is an important parameter for polaronic transport. Therefore, in our analysis and discussion of electrical parameters we use the exact composition of glasses throughout the entire manuscript.

Conductivity isotherms of B-4 glass are shown in Figure 1 and are typical spectra for all IBP glasses studied in this work.

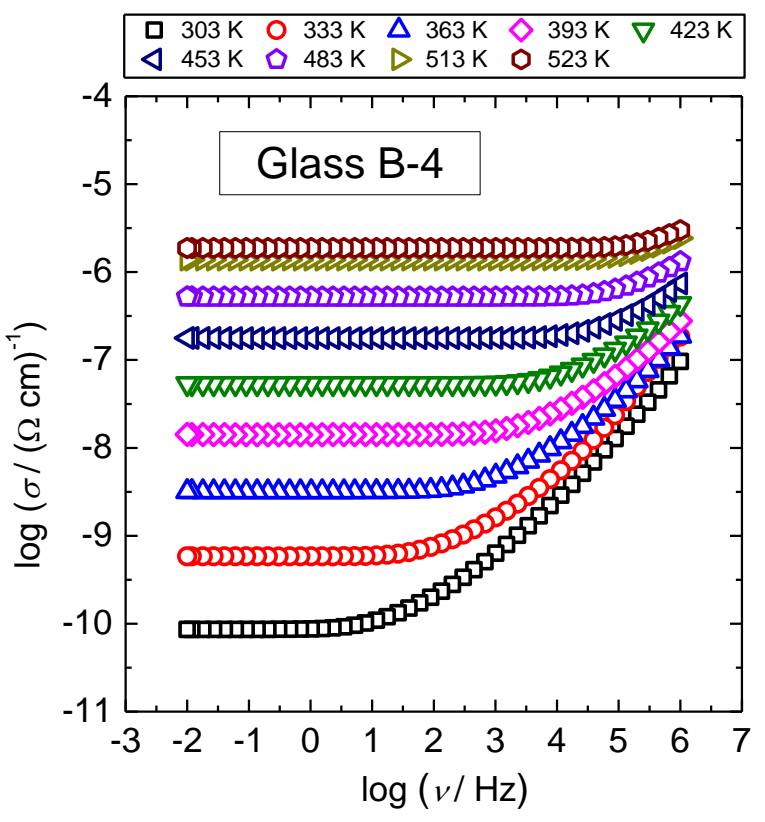

Figure 1. Conductivity spectra for B-4 glass. 
Normally, each isotherm exhibits two features, a plateau at lower frequencies that corresponds to the DC conductivity and dispersion at higher ones. The dispersive behavior is more evident at lower temperatures and frequencies, and shifts to higher frequencies with temperature. In Figure 1 , the conductivity dispersion for B-4 glass is visible for temperatures up to $483 \mathrm{~K}$. Further, it can be seen that DC conductivity is thermally activated whereas conductivity dispersion shows a weak temperature dependence. In the following, we present in detail the analysis of both quantities in terms of their temperature and compositional dependence.

\subsection{Conductivity}

It is well-known that above room temperature conduction in iron phosphate-based glasses is due to phonon-assisted hopping of polarons between nearest neighboring sites [1-7] and the DC conductivity is thermally activated with characteristic activation energy. The temperature dependence of DC conductivity, $\sigma_{\mathrm{DC}}$, in this temperature range is usually expressed by Austin-Mott's relation $[1,2,5]$ :

$$
\sigma_{\mathrm{DC}}=\left(\sigma_{0} / \mathrm{T}\right) \exp \left(\left(-E_{\mathrm{DC}}\right) /\left(\mathrm{k}_{\mathrm{B}} T\right)\right)
$$

where $\sigma_{0}$ is the pre-exponential factor, $E_{\mathrm{DC}}$ is the activation energy for the DC conductivity, $\mathrm{k}_{\mathrm{B}}$ is the Boltzmann constant and $T$ is the temperature $(\mathrm{K})$. In this relation, the pre-exponential factor, $\sigma_{0}$, contains important parameters for polaronic transport according to the relation:

$$
\left.\sigma_{0}=\left(C(1-C) v_{\mathrm{ph}} e^{2}\right) /\left(\mathrm{R} \mathrm{k}_{\mathrm{B}}\right)\right) \exp (-2 \alpha \mathrm{R}),
$$

where $C$ is the fraction of transition metal (TM) ions in lower oxidation state to total TM ion content and $R$ is the average spacing between transition metal ions $\left(R=N^{\wedge}(-1 / 3)\right), v_{\mathrm{ph}}$ is the phonon frequency $\left(\approx 10^{12}-10^{13} \mathrm{~Hz}\right), \alpha$ is the rate of wave function decay, $e$ is the electronic charge. The DC-conductivity variation with $1 / T$ for selected glasses is shown in Figure 2a.
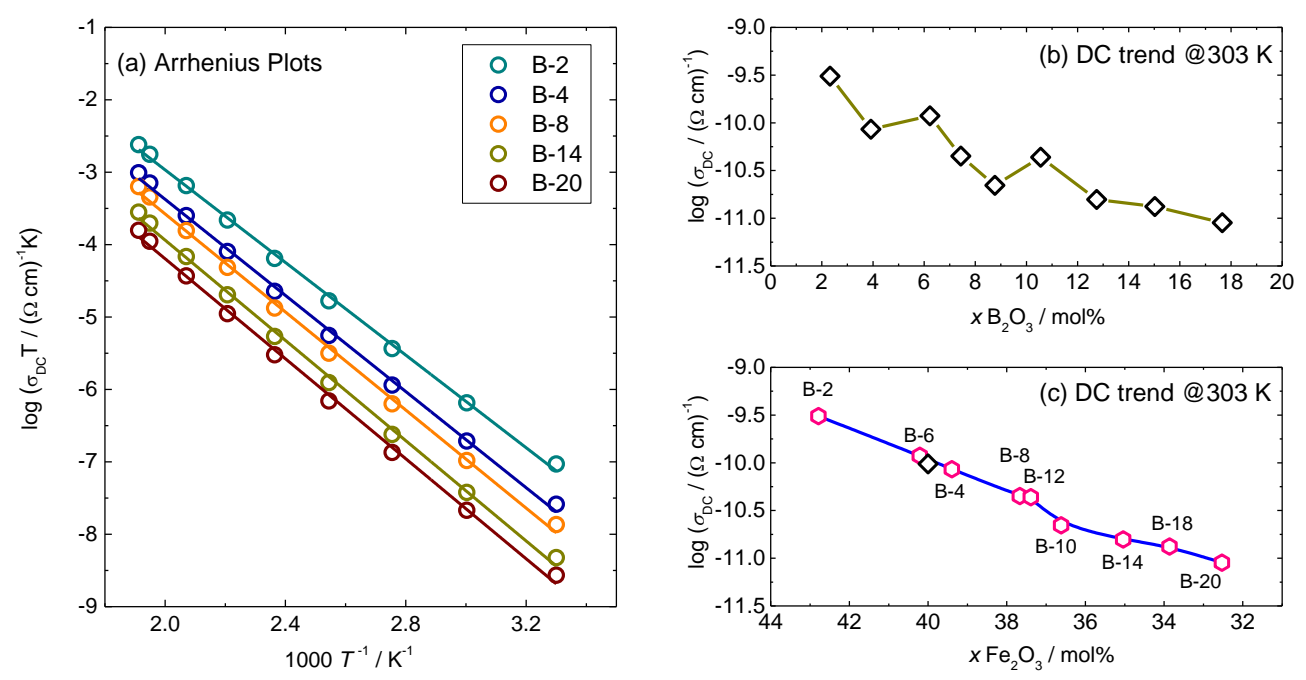

Figure 2. (a). Temperature dependence of DC conductivity $\left(\log \left(\sigma_{\mathrm{DC}} T\right)\right.$ vs. $\left.1 / \mathrm{T}\right)$ for selected glasses from $x \mathrm{~B}_{2} \mathrm{O}_{3}-(100-x)\left[40 \mathrm{Fe}_{2} \mathrm{O}_{3}-60 \mathrm{P}_{2} \mathrm{O}_{5}\right]$ series and $(\mathbf{b}, \mathbf{c})$ DC-conductivity at $303 \mathrm{~K}$ as a function of $\mathrm{B}_{2} \mathrm{O}_{3}$ and $\mathrm{Fe}_{2} \mathrm{O}_{3}$ content, respectively, for glasses from $x \mathrm{~B}_{2} \mathrm{O}_{3}-(100-x)\left[40 \mathrm{Fe}_{2} \mathrm{O}_{3}-60 \mathrm{P}_{2} \mathrm{O}_{5}\right]$ series. Solid lines in (a) represent the least-square linear fits to experimental data, whereas lines in $(\mathbf{b}, \mathbf{c})$ are drawn as guides for the eye. Black open diamond symbol in (c) is the experimental data for $40 \mathrm{Fe}_{2} \mathrm{O}_{3}-60 \mathrm{P}_{2} \mathrm{O}_{5}$ glass reported in [30].

The activation energy for DC conductivity, $E_{\mathrm{DC}}$, for each glass is calculated from the slope of $\log \left(\sigma_{\mathrm{DC}} T\right)$ vs. $1000 / T$ and listed in Table 2 along with the values of pre-exponential factor and DC conductivity. The values for DC conductivity at $303 \mathrm{~K}$ for all glasses are between $3.08 \times 10^{-10}(\Omega \mathrm{cm})^{-1}$ 
and $8.97 \times 10^{-12}(\Omega \mathrm{cm})^{-1}$ and activation energy changes from 0.63 to $0.69 \mathrm{eV}$ which is in good agreement with the values of various iron phosphate-based glasses [6].

Table 2. DC conductivity, $\sigma_{\mathrm{DC}}$, activation energy, $E_{\mathrm{DC}}$ and pre-exponential factor, $\sigma_{0}$, for all studied glasses.

\begin{tabular}{|c|c|c|c|}
\hline Glass & $\begin{array}{c}\sigma_{\mathrm{DC}}{ }^{\mathrm{a}} /(\Omega \\
\mathrm{cm})^{-1} \\
\pm 0.5 \%\end{array}$ & $\begin{array}{c}E_{\mathrm{DC}} / \mathrm{eV} \\
\pm 0.5 \%\end{array}$ & $\begin{array}{c}\log \left(\sigma_{0} /(\Omega \mathrm{cm})^{-1} \mathrm{~K}\right) \\
\pm 0.5 \%\end{array}$ \\
\hline B-2 & $3.08 \times 10^{-10}$ & 0.63 & 3.43 \\
\hline B-4 & $8.56 \times 10^{-11}$ & 0.66 & 3.26 \\
\hline B-6 & $1.19 \times 10^{-10}$ & 0.65 & 3.27 \\
\hline B-8 & $4.49 \times 10^{-11}$ & 0.67 & 3.19 \\
\hline B-10 & $2.21 \times 10^{-11}$ & 0.69 & 3.14 \\
\hline B-12 & $4.36 \times 10^{-11}$ & 0.67 & 3.13 \\
\hline B-14 & $1.57 \times 10^{-11}$ & 0.69 & 2.99 \\
\hline B-18 & $1.33 \times 10^{-11}$ & 0.69 & 2.92 \\
\hline B-20 & $8.97 \times 10^{-12}$ & 0.69 & 2.71 \\
\hline
\end{tabular}

The dependence of DC conductivity of glasses upon $\mathrm{B}_{2} \mathrm{O}_{3}$ and $\mathrm{Fe}_{2} \mathrm{O}_{3}$ content is shown in Figure $2 \mathrm{~b}, \mathrm{c}$. The $\mathrm{DC}$ conductivity decreases perfectly linearly for almost two orders of magnitude with decreasing $\mathrm{Fe}_{2} \mathrm{O}_{3}$ content, whereas it shows a scattered decrease with a simultaneous increase in $\mathrm{B}_{2} \mathrm{O}_{3}$. Observed trends suggest that the dominant parameter for the polaronic transport in these glasses is $\mathrm{Fe}_{2} \mathrm{O}_{3}$ content and not the addition of $\mathrm{B}_{2} \mathrm{O}_{3}$. Interestingly, the DC conductivity of binary $40 \mathrm{Fe}_{2} \mathrm{O}_{3}-60 \mathrm{P}_{2} \mathrm{O}_{5}$ mol.\% glass without $\mathrm{B}_{2} \mathrm{O}_{3}$ which we previously reported [30] lies precisely on the linear dependence of DC conductivity versus $\mathrm{Fe}_{2} \mathrm{O}_{3}$ content of the present glass system, see the black symbol in Figure 2c. This further supports our conclusion that the polaronic transport in these glasses is controlled solely by the iron oxide content and hence, polaron number density. Here, it should be noted that the polaron number density depends not only on the total amount of $\mathrm{Fe}_{2} \mathrm{O}_{3}$, but also on the fraction of $\mathrm{Fe}^{2+}$ and $\mathrm{Fe}^{3+}$ ions. For the $\mathrm{Fe}^{2+} / \mathrm{Fe}_{\text {tot }}$ ratio $\leq 0.5$ the polaron number density is determined by the product of number density of the total iron ions and fraction of ferrous ions, whereas for $\mathrm{Fe}^{2+} / \mathrm{Fe}_{\text {tot }}$ ratio $>0.5$ it is determined as a product of the number density of the total iron ions and the fraction of ferric ions [3,4,30]. In the previous structural study of this glass system [24], it was shown that there is no significant variation in $\mathrm{Fe}^{2+} / \mathrm{Fe}_{\text {tot }}$ ratio since the fraction of ferrous ions for selected glasses changes from 0.16 to 0.22 . Therefore, we can approximate $\mathrm{Fe}^{2+} / \mathrm{Fe}_{\text {tot }}$ ratio to be constant throughout the entire series, which allows us to assume that the polaron number density is proportional to the overall $\mathrm{Fe}_{2} \mathrm{O}_{3}$ content. The values of polaron number density calculated using the average value of $\mathrm{Fe}^{2+} / \mathrm{Fe}_{\text {tot }}=0.19$ for all glasses are given in Table 3. For example, the polaron number density, $\mathrm{Nv}$ (polarons), for B-2 glass is calculated by multiplying number density of the total iron ions, $\mathrm{N}$ (Fe ions), see Table 3 , and 0.19 $\left(10.7 \times 10^{21} \mathrm{~cm}^{-3} \times 0.19=2.03 \times 10^{21} \mathrm{~cm}^{-3}\right)$. Indeed, the DC conductivity exhibits a similarly linear increase with increasing polaron number density, see Figure 3.

Going further in the analysis of the polaronic transport in these glasses we turn our attention to the changes in the pre-exponential factor and parameters it contains, see Table 2. According to Austin-Mott's theory of small polaron hopping, the conduction process can be characterized by either adiabatic or non-adiabatic hopping. In adiabatic hopping, the electron is at all times relaxed in the potential well of its lattice distortion and hence can respond rapidly to the displacement of the lattice due to the polarization field, while in non-adiabatic hopping the chance of the electron tunneling is rather small $[1,2,5]$. Hence, in adiabatic hopping conduction, the tunneling term $\exp (-2 \alpha R)$ in Equation (2) is approximately 1, thus $\alpha R$ becomes negligible. Although in literature there has been much discussion about whether adiabatic or non-adiabatic hopping picture is valid for oxide glasses at high temperatures [3,4], it was shown from DC conductivity data that non-adiabatic hopping model is more suited to describe polaron transport in iron phosphate-based glasses [27]. In order to check the adiabatic or non-adiabatic nature of the hopping conduction in glasses from this study, we have 
analyzed the dependence of $\log \left(\sigma_{\mathrm{DC}} T\right)$ vs. activation energy, $E_{\mathrm{DC}}$ at a fixed experimental temperature $T=423 \mathrm{~K}$, see Figure 4 . In such a plot, the slope equals to $1 \mathrm{k}_{\mathrm{B}} T$ which enables us to determine the mechanism of the polaron hopping in the following way. If the experimental temperature is approximately equal to the temperature obtained from the slope, the process is adiabatic. On the other hand, if the temperatures differ, the process is non-adiabatic.

Table 3. Summary of quantities and parameters of polaronic transport for glasses from $x \mathrm{~B}_{2} \mathrm{O}_{3}-$ $(100-x)\left[40 \mathrm{Fe}_{2} \mathrm{O}_{3}-60 \mathrm{P}_{2} \mathrm{O}_{5}\right]$ series.

\begin{tabular}{|c|c|c|c|c|c|c|}
\hline Glass & $\begin{array}{c}N \text { (Fe ions) } \times \\
10^{-21} / \mathrm{cm}^{-3}\end{array}$ & $\begin{array}{c}N_{\mathrm{v}} \text { (Polarons) } \times \\
10^{-21} / \mathrm{cm}^{-3}\end{array}$ & $R=N^{-1 / 3} / \AA ̊$ & $r_{\mathrm{p}} / \AA ̊ \AA$ & $(\Delta \varepsilon \cdot T) / \mathrm{K}$ & $\begin{array}{c}<r_{\text {LOC }}{ }^{2}(\infty)>^{1 / 2} \\
/ \AA\end{array}$ \\
\hline B-2 & 10.7 & 2.03 & 4.54 & 1.93 & 4937 & 2.64 \\
\hline B-4 & 9.65 & 1.83 & 4.70 & 1.89 & 4098 & 2.53 \\
\hline B-6 & 9.84 & 1.87 & 4.67 & 1.88 & 4476 & 2.61 \\
\hline B-8 & 9.35 & 1.78 & 4.75 & 1.91 & 4767 & 2.84 \\
\hline B-10 & 9.09 & 1.73 & 4.79 & 1.93 & 4165 & 2.62 \\
\hline B-12 & 9.62 & 1.83 & 4.70 & 1.89 & 4828 & 2.75 \\
\hline B-14 & 8.77 & 1.67 & 4.85 & 1.95 & 4338 & 2.73 \\
\hline B-18 & 8.67 & 1.65 & 4.87 & 1.96 & 4365 & 2.75 \\
\hline B-20 & 8.30 & 1.58 & 4.94 & 1.99 & 5060 & 3.03 \\
\hline
\end{tabular}

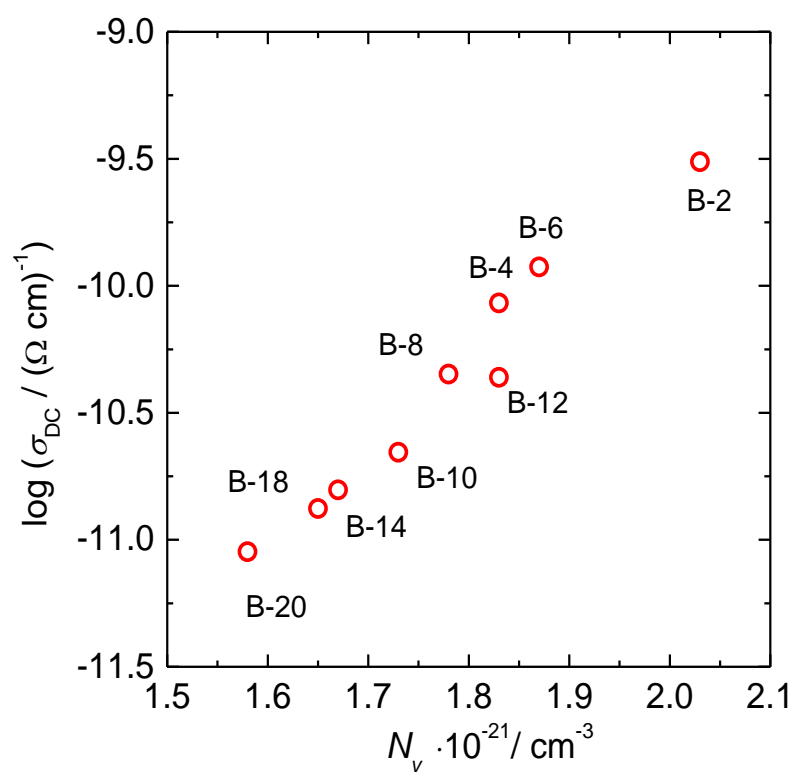

Figure 3. DC conductivity at $303 \mathrm{~K}$ versus polaron number density, $\mathrm{Nv}$, for glasses from $x \mathrm{~B}_{2} \mathrm{O}_{3}-(100-x)\left[40 \mathrm{Fe}_{2} \mathrm{O}_{3}-60 \mathrm{P}_{2} \mathrm{O}_{5}\right]$ series.

The value of the temperature obtained from the slope for glasses in this study is $T=253 \mathrm{~K}$ which is very different from the chosen experimental temperature, $T=423 \mathrm{~K}$ This indicates the non-adiabatic hopping of small polarons in these glasses. This result is in accordance with the non-adiabatic hopping mechanism found in similar iron phosphate-based glasses: $x \mathrm{~B}_{2} \mathrm{O}_{3}-(40-x) \mathrm{Fe}_{2} \mathrm{O}_{3}-60 \mathrm{P}_{2} \mathrm{O}_{5}(0 \leq x \leq 20$ mol.\%) [27], $x \mathrm{HfO}_{2}-(40-x) \mathrm{Fe}_{2} \mathrm{O}_{3}-60 \mathrm{P}_{2} \mathrm{O}_{5} \quad(0 \leq x \leq 8 \mathrm{~mol} . \%), \quad x \mathrm{CeO}_{2}-(40-x) \mathrm{Fe}_{2} \mathrm{O}_{3}-60 \mathrm{P}_{2} \mathrm{O}_{5} \quad(0 \leq x \leq 8 \mathrm{~mol} . \%)$ and $x \mathrm{HfO}_{2}-(38-x) \mathrm{Fe}_{2} \mathrm{O}_{3}-2 \mathrm{~B}_{2} \mathrm{O}_{3}-60 \mathrm{P}_{2} \mathrm{O}_{5}\left(2 \leq x \leq 6 \mathrm{~mol} . \%\right.$ ) [30], $\mathrm{CaO}-\mathrm{BaO}-\mathrm{Fe}_{2} \mathrm{O}_{3}-\mathrm{P}_{2} \mathrm{O}_{5}$ [31], $\mathrm{Fe}_{2} \mathrm{O}_{3}-\mathrm{Bi}_{2} \mathrm{O}_{3}-$ $\mathrm{P}_{2} \mathrm{O}_{5}$ [32] and $\mathrm{Fe}_{2} \mathrm{O}_{3}-\mathrm{CaO}-\mathrm{P}_{2} \mathrm{O}_{5}$ [33]. 


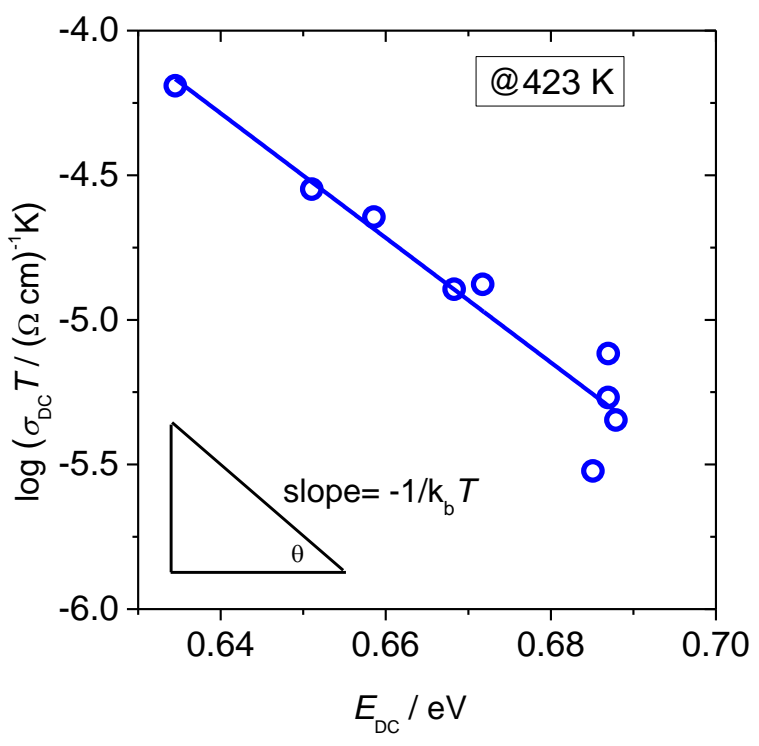

Figure 4. $\log \left(\sigma_{D C} T\right)$ versus $E_{D C}$ for studied $x \mathrm{~B}_{2} \mathrm{O}_{3}-(100-x)\left[40 \mathrm{Fe}_{2} \mathrm{O}_{3}-60 \mathrm{P}_{2} \mathrm{O}_{5}\right]$ glass series. Each point represents an individual glass sample. Solid line represents the least-squares linear fit to experimental data.

Going back to the influence of $\mathrm{B}_{2} \mathrm{O}_{3}$ on the polaronic transport in these glasses, it seems that the DC conductivity is strongly controlled by the content of $\mathrm{Fe}_{2} \mathrm{O}_{3}$ and independent of the $\mathrm{B}_{2} \mathrm{O}_{3}$ addition and the structural changes it introduces. The IR and Mössbauer spectroscopy study [24] showed that boron enters phosphate network as $\mathrm{BO}_{4}$ tetrahedral units forming $\mathrm{B}-\mathrm{O}-\mathrm{B}$ and/or $\mathrm{B}-\mathrm{O}-\mathrm{P}$ type bonds rather than $\mathrm{B}-\mathrm{O}-\mathrm{Fe}$ bonds. Consequently, the iron environment in these glasses is not significantly affected by the addition of $\mathrm{B}_{2} \mathrm{O}_{3}$. Both $\mathrm{Fe}^{2+}$ and $\mathrm{Fe}^{3+}$ ions have distorted octahedral coordination in all glasses similarly as in many other iron phosphate systems [9,17]. In addition, the O/P ratio for these glasses changes from 3.65 to 4.01 , see Table 1, which suggests the presence of pyrophosphate $\left(\mathrm{Q}^{1}\right)$ and ortophosphate $\left(\mathrm{Q}^{0}\right)$ units in phosphate network with a slight tendency for depolymerization with increasing $\mathrm{B}_{2} \mathrm{O}_{3}$ content. The fact that the structural environment of iron ions remains unaffected by the introduction of borate units in the phosphate network can explain why the DC conductivity is not directly dependent on $\mathrm{B}_{2} \mathrm{O}_{3}$ addition.

\subsection{Frequency-Dependent Conductivity and Scaling Properties}

While the analysis of DC conductivity and its temperature dependence gives important information on the long-range transport of charge carriers in glasses, features of the frequency-dependent conductivity provide insights into the processes of their localized motions. A relatively simple, but very helpful means of an analysis of the conductivity spectra over a wide range of frequency and temperatures is based on the application of various scaling procedures. In this respect, one of the simplest and widely used scaling procedures is Summerfield scaling $[34,35]$ which uses experimentally easily assessable parameter-DC conductivity as a scaling factor. The Summerfield scaling is expressed by the relation: $\left(\sigma(v, T) / \sigma_{\mathrm{DC}}(T)\right)=F\left(v / T \sigma_{\mathrm{DC}}(T)\right)$ and it can be understood as a mobility scaling; it is indicative that the role of temperature is to only speed up the charge carrier dynamics with increasing temperature without changing the conduction mechanism.

For all glasses in this study, Summerfield scaling procedure yields a perfect master-curve demonstrating that the time-temperature superposition (TTS) is valid and that the conductivity mechanism is temperature-invariant, as shown for B-2, B-8, B-14 and B-20 glasses in Figure 5. This is in line with the scaling properties of various oxide glasses that exhibit ionic [36,37] or polaronic conductivity [30,37]. Interestingly, our previous study on $x \mathrm{~B}_{2} \mathrm{O}_{3}-(40-x)-\mathrm{Fe}_{2} \mathrm{O}_{3}-60 \mathrm{P}_{2} \mathrm{O}_{5}(x=0-20$, mol.\%) system showed that glass with $2 \mathrm{~mol} . \%$ of $\mathrm{B}_{2} \mathrm{O}_{3}$ fails to produce a master-curve when Summerfield 
scaling procedure is applied [27]. The cause of this deviation was found to be related to the influence of structure on the polaronic conductivity, i.e., local structural disorder induced by the addition of a small amount of $\mathrm{B}_{2} \mathrm{O}_{3}$ which allows changes of the number density of polarons and/or their pathways with temperature.
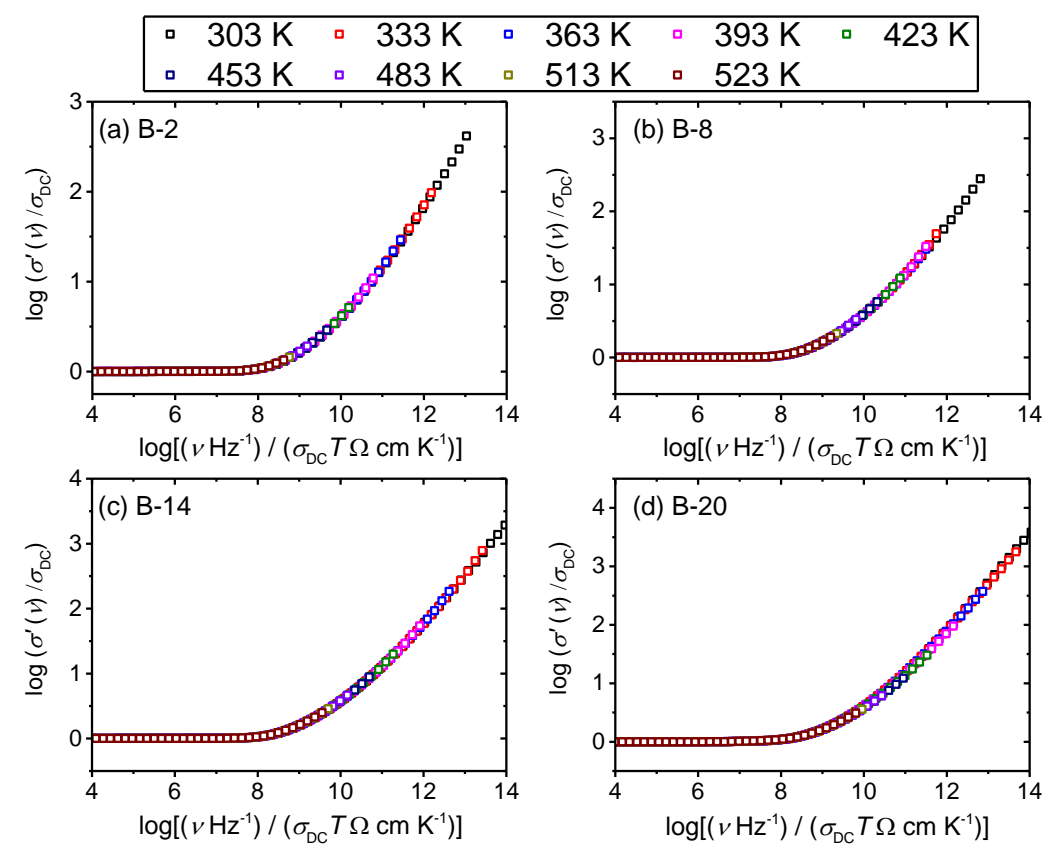

Figure 5. Conductivity spectra scaled according to the Summerfield scaling procedure for (a) B-2, (b) B-8, (c) B-14 and (d) B-20 glasses.

In the glass system studied in this work, we have not observed the same effect and glasses with small amounts of $\mathrm{B}_{2} \mathrm{O}_{3}$ obey Summerfield scaling (cf. with Figure 5 for B-2 glass). This result can be related to the fact that within this glass series, $\mathrm{B}_{2} \mathrm{O}_{3}$ is added at the expense of both $\mathrm{Fe}_{2} \mathrm{O}_{3}$ and $\mathrm{P}_{2} \mathrm{O}_{5}$ which has a different influence on the cross-linking of the iron phosphate network. Previous structural study of these two glass systems [24] shows that a gradual substitution of $\mathrm{Fe}_{2} \mathrm{O}_{3}$ and $\mathrm{P}_{2} \mathrm{O}_{5}$ by $\mathrm{B}_{2} \mathrm{O}_{3}$ weakens the network structure as evidenced by the decrease in $T_{g}$, whereas an opposite trend is observed for glasses where only $\mathrm{Fe}_{2} \mathrm{O}_{3}$ was replaced by $\mathrm{B}_{2} \mathrm{O}_{3}$. For this reason, it seems likely that at low amounts of $\mathrm{B}_{2} \mathrm{O}_{3}$, small changes in the strength and rigidity of the iron phosphate network affect the mechanism of polaronic transport, i.e., by enabling or disabling the temperature dependence of polaron number density and/or conduction pathways. Furthermore, it is interesting to explore the influence of the glass composition and structure on the conductivity dispersion by applying super-scaling in which all individual master-curves within the glass series are superimposed onto each other. Figure $6 \mathrm{a}, \mathrm{b}$ shows the result of such super-scaling for all investigated glasses. As can be seen from the Figure 6a individual master-curves do not accurately overlap and a super-master curve could not be obtained. There are two possible reasons for such a result: either the shape of the conductivity dispersion changes or/and individual master curves get shifted along the $x$-axis with the changes in the glass composition.

Intending to detect possible changes in the shape of the conductivity master curves, we have shifted the individual master curves along the $x$-axis in an attempt to produce a super-master curve, see Figure $6 \mathrm{~b}$. In the shifting procedure, the master-curve of B-2 glass was taken as a reference curve. All master-curves except that for B-20 glass perfectly overlap when shifted which suggests that the shape of their conductivity dispersion is the same. On the other hand, the master-curve for B-20 glass exhibits evidently different shape of the frequency-dependent conductivity, thus failing to superimpose onto the super-master curve of glasses from B-2 to B-18. Although it is hard to argue about the origin(s) of different shape of the conductivity dispersion for B-20 glass without more detailed structural 
characterization of the whole glass series and investigation of the glasses containing higher $\mathrm{B}_{2} \mathrm{O}_{3}$ amounts, it is likely related to the structural features of the glass at highest $\mathrm{B}_{2} \mathrm{O}_{3}$ content within this series. Possibly, the extensive inclusion of $\mathrm{BO}_{4}$ tetrahedra and formation of $\mathrm{B}-\mathrm{O}-\mathrm{P}$ and $\mathrm{B}-\mathrm{O}-\mathrm{B}$ bonds in this glass influences the local dynamics of polarons.
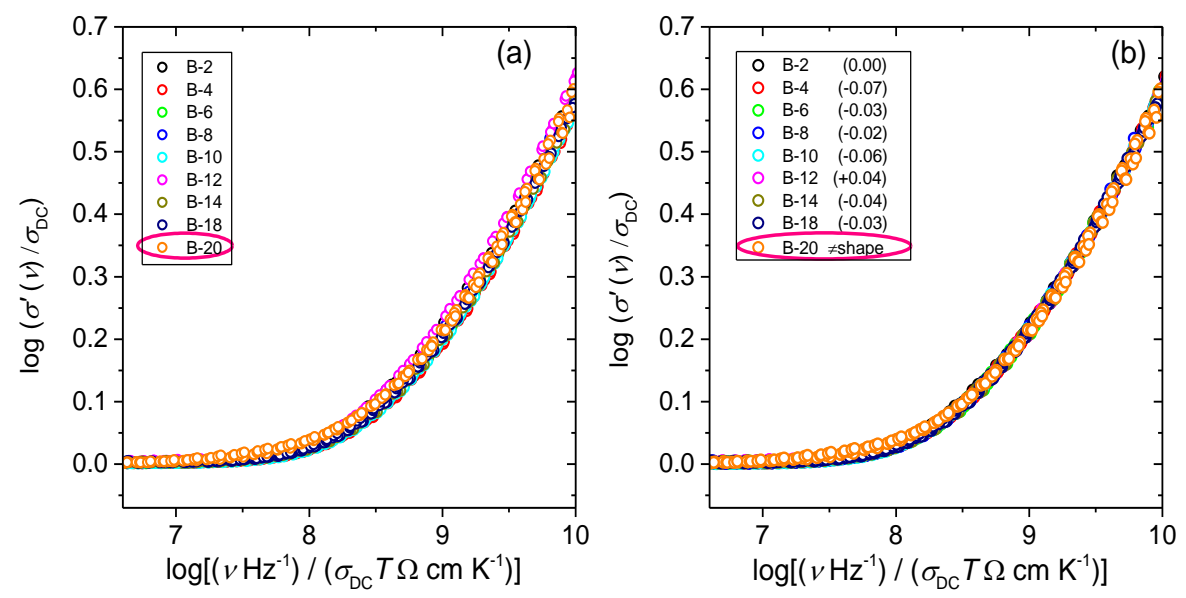

Figure 6. (a) Construction of super-master curve of the conductivity isotherms using the Summerfield scaling procedure for $x \mathrm{~B}_{2} \mathrm{O}_{3}-(100-x)\left[40 \mathrm{Fe}_{2} \mathrm{O}_{3}-60 \mathrm{P}_{2} \mathrm{O}_{5}\right]$ glass series and (b) individual conductivity master-curves shifted along the $x$-axis.

The values of the shift needed to produce a super-master curve for B-2 to B-18 glasses are given in the legend of Figure $6 \mathrm{~b}$. Considering the magnitude and direction of the shift, it can be seen that values are very small and they do not imply any trend with the change of glass composition. The shift in conductivity super-master plot has been reported for various series of ionically conducting oxide glasses where it has been correlated with the alkali oxide content and hence number density of mobile ions [38,39] as well as changes in the typical length of the hop of the ions with their number density [40]. Recently, we have shown that the Summerfield master-curves of polaronically conducting iron phosphate glasses of similar composition and structure, but widely ranging fraction of ferrous ions $\left(0.23 \leq \mathrm{Fe}^{2+} / \mathrm{Fe}_{\text {tot }} \leq 0.58\right)$ also exhibit a shift on the $x$-axis upon super-scaling [30]. Our analysis revealed that the observed shift can be correlated to the product of polaron number density, $N_{v}$ and the spatial extent of localized motions of polarons, $\left\langle\mathrm{r}^{2} \mathrm{LOC}(\infty)>^{1 / 2}\right.$. Therefore, it is further of interest to consider the characteristic spatial extent of localized hopping of polarons which can be assessed from the scaling property of the permittivity spectra.

\subsection{Scaling of Permittivity Spectra and Length Scales of Polaronic Transport}

The spectra of the real part of permittivity, $\varepsilon^{\prime}(v)$, at different temperatures for B-10 glass is shown in Figure 7a as a representative for all other glasses in this study. At each temperature, permittivity spectrum exhibits a typical frequency-dependence; at higher frequencies, the real part of the permittivity tends to a constant value, $\varepsilon^{\prime}{ }_{\infty}$, which results from rapid polarization processes occurring in the glasses under an applied field whereas, with decreasing frequency, it increases and approaches a limiting low frequency plateau denoted as the low-frequency static permittivity, $\varepsilon^{\prime}{ }_{\mathrm{s}}$. The static permittivity is associated with the polarization effects of the polarons with respect to the immobile glass matrix and determines the difference $\Delta \varepsilon=\varepsilon^{\prime}{ }_{s}-\varepsilon^{\prime}{ }_{\infty}$ called dielectric strength of relaxation $[40,41]$.

Here it should be noted that permittivity spectra of polaronic glasses exhibit a well-defined low frequency plateau, as shown in Figure 7a, which is not the case for most ionically conducting glasses since in their spectra effects of electrode polarization dominate at low frequency, hence, masking the permittivity plateau. In contrast, polaronic glasses exhibit a small increase of the real part of permittivity below the point corresponding to static permittivity due to a negligible electrode polarization and 
surface effects. The imaginary part of permittivity, $\varepsilon^{\prime \prime}$, increases linearly with decreasing frequency in a $\log -\log$ plot, see Figure 7c, due to the contribution of DC conduction [42].
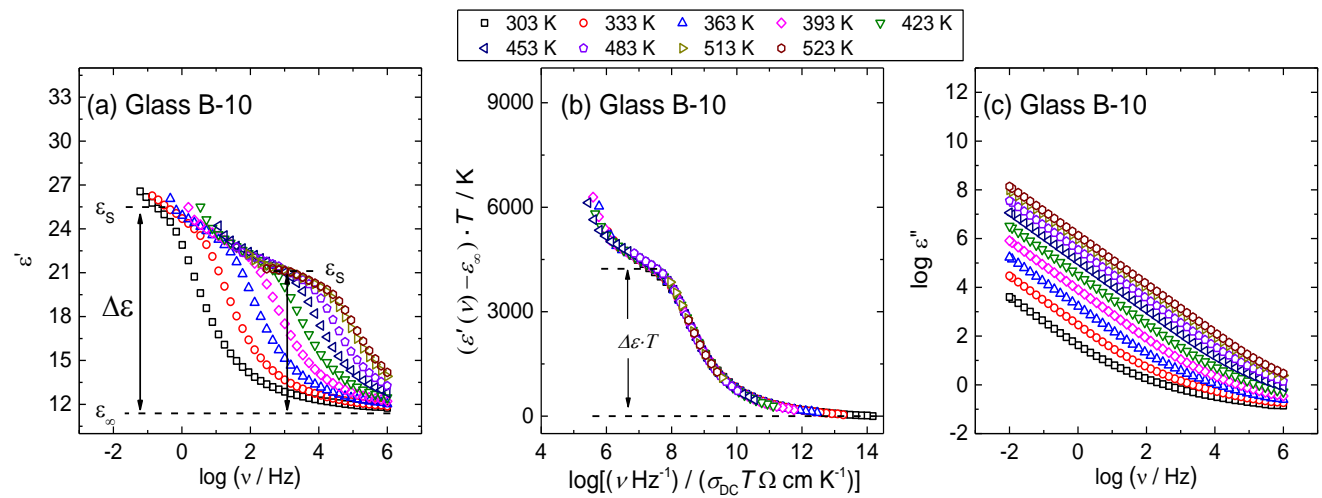

Figure 7. (a) Real permittivity spectra at different temperatures, (b) their scaled representation obtained using Summerfield scaling procedure and (c) imaginary permittivity spectra at different temperatures for glass B-10.

Since permittivity and conductivity are directly related quantities, the scaling properties of conductivities are mirrored in the scaling properties of permittivity. The Summerfield scaling procedure for the permittivity spectra includes rescaling of the real part of permittivity by subtracting $\mathcal{E}_{\infty}^{\prime}$ and multiplying by $T$, while the $x$-axis is scaled by the product $\left(T \sigma_{\mathrm{DC}}(T)\right.$ ). Expectedly, from the results of conductivity scaling, the Summerfield scaling procedure yields a perfect permittivity master curve for all glasses in this study. The representative plot of permittivity master-curve is shown for B-10 glass in Figure $7 \mathrm{~b}$. For each glass, the scaling of the permittivity spectra yields a parameter $\Delta \varepsilon$ $T$ which can be related to the typical spatial extent of localized motions of polarons, $<\mathrm{r}^{2}$ LOC $(\infty)>>^{1 / 2}$. via relation $[30,43]$ :

$$
<r_{\mathrm{LOC}^{2}}{ }^{2}(\infty)>^{1 / 2}=6 \mathrm{k}_{\mathrm{B}} \varepsilon_{0} \Delta \varepsilon T / N_{\mathrm{v}} \mathrm{q}^{2}
$$

where $\mathrm{k}_{\mathrm{B}}$ is Boltzmann's constant, $\varepsilon_{0}$ is the permittivity of free space and $N_{\mathrm{v}}$ is the number density of polarons. For each glass, the parameter $\Delta \varepsilon T$ is determined from the onset of the static permittivity plateau in permittivity master-curve as shown graphically for glass B-10 in Figure $7 \mathrm{~b}$. The obtained values of the extent of the localized motions of polarons are given in Table 3 and shown in Figure 8.

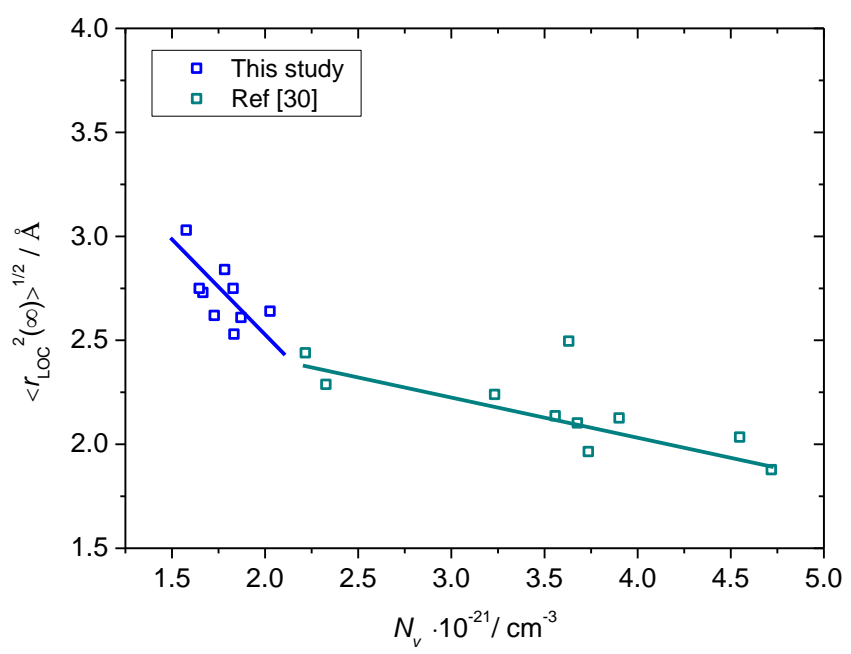

Figure 8. Spatial extent of localized motions of polarons, $\left\langle r_{\mathrm{LOC}}{ }^{2}(\infty)\right\rangle^{1 / 2}$, as a function of the number density of polarons for $x \mathrm{~B}_{2} \mathrm{O}_{3}-(100-x)\left[40 \mathrm{Fe}_{2} \mathrm{O}_{3}-60 \mathrm{P}_{2} \mathrm{O}_{5}\right]$ glasses from this study and $\mathrm{HfO}_{2}-\mathrm{Fe}_{2} \mathrm{O}_{3}-\mathrm{P}_{2} \mathrm{O}_{5}$, $\mathrm{CeO}_{2}-\mathrm{Fe}_{2} \mathrm{O}_{3}-\mathrm{P}_{2} \mathrm{O}_{5}$ and $\mathrm{HfO}_{2}-\mathrm{Fe}_{2} \mathrm{O}_{3}-\mathrm{B}_{2} \mathrm{O}_{3}-\mathrm{P}_{2} \mathrm{O}_{5}$ glasses from Ref. [30]. Lines are drawn as guides for the eye. 
As can be seen from Table 3 and Figure 8 , the value of $\left\langle r_{\operatorname{LOC}}{ }^{2}(\infty)\right\rangle^{1 / 2}$ increases from $2.53 \AA$ to $3.03 \AA$ as the polaron number density, $N_{\mathrm{v}}$, decreases from $2.03 \times 10^{21} \mathrm{~cm}^{-3}$ to $1.58 \times 10^{21} \mathrm{~cm}^{-3}$ for B-20 glass. Such a trend corroborates our previous findings [30] that the spatial extent of the localized polaron hopping decreases with increasing polaron number density and represents a realistic estimate of the extent of polaron cavity. Indeed, from Table 3 it is visible that the magnitude of the $\left.<r_{\text {LOC }}{ }^{2}(\infty)\right\rangle^{1 / 2}$ values is close to that of polaron radius, $r_{p}$, calculated from the equation proposed by Bogomolov and Mirilin: $r_{p}=(1 / 2)(\pi / 6 N)^{1 / 3}$ where $N$ is the total number of iron ions [44,45]. Also, it should be noted that the values of $\left\langle r_{\mathrm{LOC}}{ }^{2}(\infty)\right\rangle^{1 / 2}$ for these glasses are higher than those obtained for glasses from $x \mathrm{HfO}_{2}-(40-x) \mathrm{Fe}_{2} \mathrm{O}_{3}-60 \mathrm{P}_{2} \mathrm{O}_{5}, 0 \leq x \leq 8 \mathrm{~mol} . \%, x \mathrm{CeO}_{2}-(40-x) \mathrm{Fe}_{2} \mathrm{O}_{3}-60 \mathrm{P}_{2} \mathrm{O}_{5}, 0 \leq x \leq 8 \mathrm{~mol} . \%$ and $x \mathrm{HfO}_{2}-(38-\mathrm{x}) \mathrm{Fe}_{2} \mathrm{O}_{3}-2 \mathrm{~B}_{2} \mathrm{O}_{3}-60 \mathrm{P}_{2} \mathrm{O}_{5} 2 \leq x \leq 6$ mol.\% series [30]. This result is in line with their lower values of polaron number density, compare Tables 3 and 3 in [30]. However, it is interesting to see that the decrease of $\left\langle r_{\mathrm{LOC}}{ }^{2}(\infty)\right\rangle^{1 / 2}$ with $N \mathrm{v}$ for the present glass system is characterized by a larger slope than that of $\mathrm{HfO}_{2}-\mathrm{Fe}_{2} \mathrm{O}_{3}-\mathrm{P}_{2} \mathrm{O}_{5}, \mathrm{CeO}_{2}-\mathrm{Fe}_{2} \mathrm{O}_{3}-\mathrm{P}_{2} \mathrm{O}_{5}$ and $\mathrm{HfO}_{2}-\mathrm{Fe}_{2} \mathrm{O}_{3}-\mathrm{B}_{2} \mathrm{O}_{3}-\mathrm{P}_{2} \mathrm{O}_{5}$ glasses [30], see Figure 8. This observation can be related either to the influence of borate units on the formation of polarons or to the inherent property of the polaronic transport in iron phosphate glasses with low $N_{\mathrm{v}}$. In order to ascertain the actual cause of this behavior, more investigations on the iron phosphate glasses with a similar range of polaron number density but free of $\mathrm{B}_{2} \mathrm{O}_{3}$ are required. These studies are underway.

Further, stimulated by the fact that all glasses in our study exhibit a well-defined static permittivity plateau which enables us to precisely determine dielectric strength, $\Delta \varepsilon$, we apply an alternative scaling procedure for conductivity spectra proposed by Sidebottom which is expressed by the form: $\left(\sigma(v, T) / \sigma_{\mathrm{DC}}(T)\right)=F\left(\nu \varepsilon_{0} \Delta \varepsilon / \sigma_{\mathrm{DC}}(T)\right)[40]$. The Sidebottom scaling procedure considers the simultaneous change in the typical hopping distance of the charge carriers with changes of their number density and it is considered as truly universal, since it applies whenever scaling is possible at all, i.e., when the shape of the conductivity dispersion does not change with temperature [45]. Figure 9 . shows that Sidebottom scaling procedure produces conductivity master-curve for B-2, B-8, B-14 and B-20 glasses and the same result was obtained for all other glasses in this study.
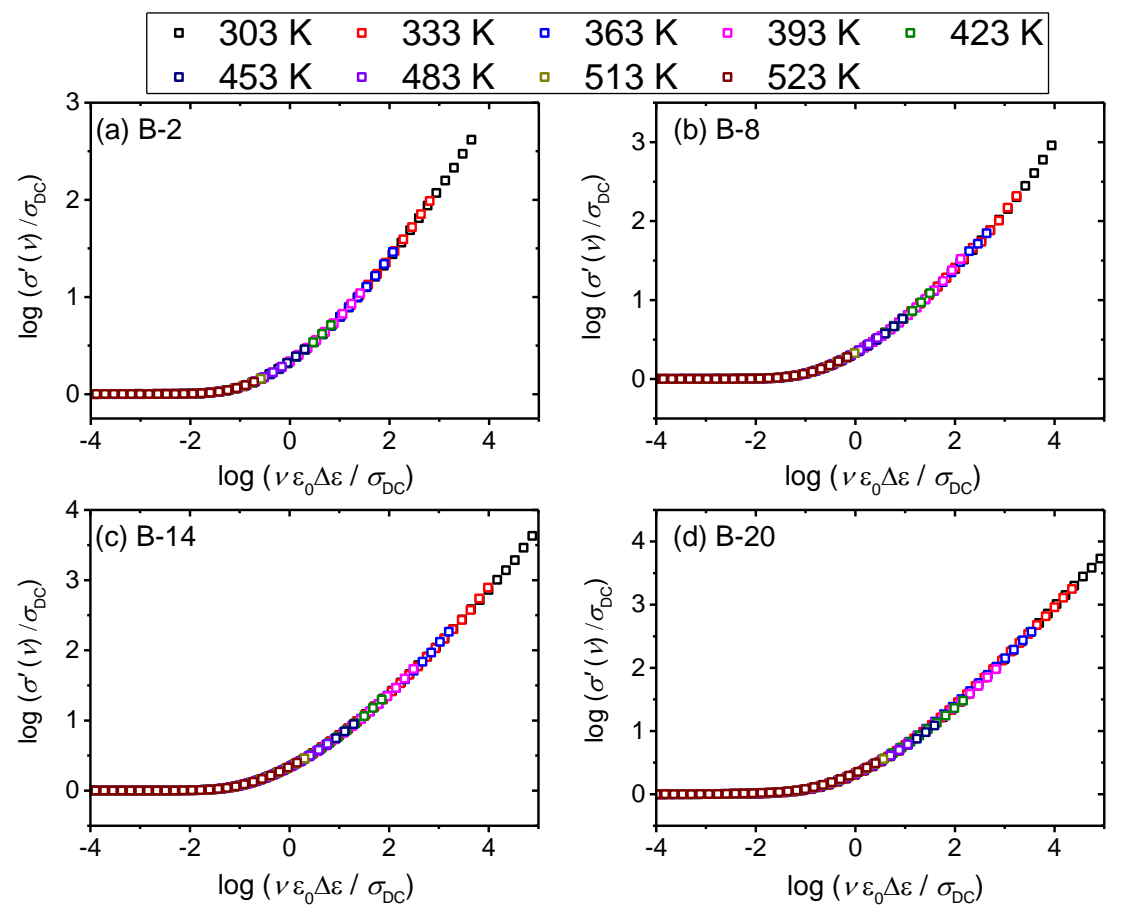

Figure 9. Conductivity spectra scaled according to the Sidebottom scaling procedure for (a) B-2, (b) B-8, (c) B-14 and (d) B-20 glasses. 
Finally, we show that Sidebottom scaling yields a perfect conductivity super-master curve for glasses from B-2 to B-18, see Figure 10. Having in mind that the Summerfield scaling failed to do so, this result implies that the lengths of a polaron hop change with composition in these glasses.
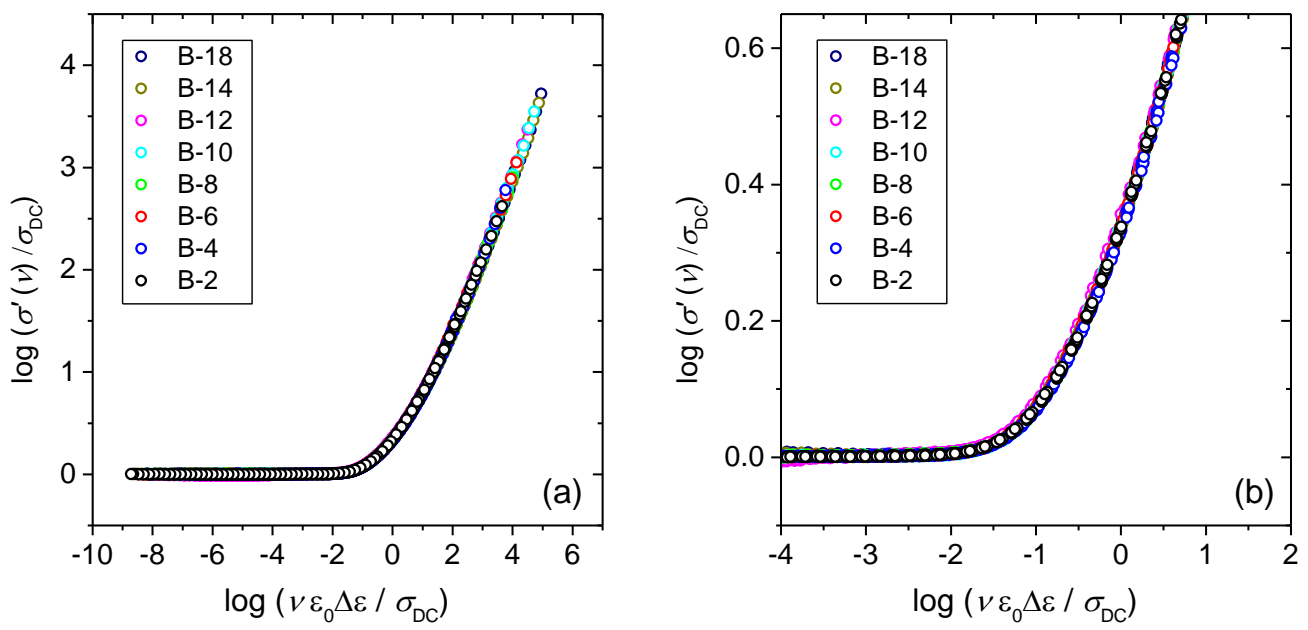

Figure 10. (a) Construction of super-master curve of the conductivity isotherms using Sidebottom scaling procedure for B-2 to B-18 glasses and (b) zoomed area to underline the observed overlap. B-20 glass is not plotted due to different shape of the conductivity dispersion.

\section{Conclusions}

The analysis of electrical properties of $x \mathrm{~B}_{2} \mathrm{O}_{3}-(100-x)\left[40 \mathrm{Fe}_{2} \mathrm{O}_{3}-60 \mathrm{P}_{2} \mathrm{O}_{5}\right], x=2-20$ mol. $\%$ nominal composition glasses in a wide range of temperatures and frequencies reveal that the DC conductivity depends strongly on the polaron number density determined by the overall amount of $\mathrm{Fe}_{2} \mathrm{O}_{3}$. The polaronic transport in all glasses is non-adiabatic. The addition of $\mathrm{B}_{2} \mathrm{O}_{3}$ is not found to be the factor that influences long-range DC conductivity in this glass system, however, it seems that it affects the short-range dynamics of polarons as evidenced in the features of the frequency-dependent conductivity. The consideration of the scaling features of conductivity spectra shows that all glasses obey Summerfield and Sidebottom scaling procedures indicating the validity of the time-temperature superposition principle. Further, the superposition of individual master curves onto each other in an attempt to produce a super-master curve revealed two important results. First, the shape of the conductivity dispersion is the same for glasses with up to 15.0 mol.\% $\mathrm{B}_{2} \mathrm{O}_{3}$ but differs for glass with $17.7 \mathrm{~mol} . \%$ $\mathrm{B}_{2} \mathrm{O}_{3}$. A different shape of the frequency-dependent conductivity of the latter glass is most probably related to the structural features of the glass at high $\mathrm{B}_{2} \mathrm{O}_{3}$ content. Second, while the Summerfield scaling procedure appears to fail, Sidebottom scaling yields a super-master curve for glasses with up to $15.0 \mathrm{~mol} \% \mathrm{~B}_{2} \mathrm{O}_{3}$, which indicates that while the time-temperature superposition principle is fulfilled, polaronic hopping lengths also change with changing polaron number density in these glasses. The calculated spatial extent of localized motions of polarons, assessed from scaled permittivity spectra, for all glasses are close in values to their polaronic radii. Interestingly, the dependence of the values of the spatial extent of localized polaron motions on the polaron number density complements well the dependence previously found for iron phosphate glasses containing $\mathrm{HfO}_{2}$ and $\mathrm{CeO}_{2}$ with larger polaron number density. However, this dependence for glasses from this study is characterized by a larger slope which could also be related to the influence of $\mathrm{B}_{2} \mathrm{O}_{3}$ on glass structure and formation of polarons.

Author Contributions: Conceptualization, L.P. and A.Š.; validation, L.P., A.Š; formal analysis, L.P.; S.F., A.Š.; investigation, L.P.; S.F., M.K., H.E., A.M.-M., A.Š.; writing—original draft preparation, L.P., A.Š.; writing-review and editing, L.P., S.F., M.K., A.M.-M.; A.Š.; visualization, L.P., A.Š.; supervision, M.K., A.M.-M.; A.Š.; project administration, A.Š.; funding acquisition, A.Š. All authors have read and agreed to the published version of the manuscript. 
Funding: This work is supported by the Croatian Science Foundation, POLAR-ION-GLASS project IP-2018-01-5425. M.K. and H.E. would like to acknowledge support by The Scientific and Technological Research Council of Turkey (TUBITAK) with the project no: 107M370.

Conflicts of Interest: The authors declare no conflict of interest.

\section{References}

1. Mott, N. Conduction in glasses containing transition metal ions. J. Non-Cryst. Solids 1968, 1, 1-17. [CrossRef]

2. Austin, I.; Mott, N. Polarons in crystalline and non-crystalline materials. Adv. Phys. 1969, 18, 41-102. [CrossRef]

3. Murawski, L.; Chung, C.; MacKenzie, J. Electrical properties of semiconducting oxide glasses. J. Non-Cryst. Solids 1979, 32, 91-104. [CrossRef]

4. Sayer, M.; Mansingh, A. Transport Properties of Semiconducting Phosphate Glasses. Phys. Rev. B 1972, 6, 4629-4643. [CrossRef]

5. Austin, I. Polaron conduction in disordered 3d oxides. J. Non-Cryst. Solids 1970, 2, 474-483. [CrossRef]

6. Šantić, A.; Moguš-Milanković, A. Charge carrier dynamics in materials with disordered structures: A case study of iron phosphate glasses. Croat. Chem. Acta 2012, 85, 245-254. [CrossRef]

7. Banday, A.; Murugavel, S. Small polaron hopping conduction mechanism in $\mathrm{LiFePO}_{4}$ glass and crystal. J. Appl. Phys. 2017, 121, 45111. [CrossRef]

8. Moguš-Milanković, A.; Day, D.E.; Šantić, B. DC conductivity and polarisation in iron phosphate glasses. Phys. Chem. Glasses 1999, 40, 69-74.

9. Fang, X.; Ray, C.S.; Mogus-Milankovic, A.; Day, D.E. Iron redox equilibrium, structure and properties of iron phosphate glasses. J. Non-Cryst. Solids 2001, 283, 162-172. [CrossRef]

10. Moustafa, Y.; El-Egili, K.; Doweidar, H.; Abbas, I. Structure and electric conduction of $\mathrm{Fe}_{2} \mathrm{O}_{3}-\mathrm{P}_{2} \mathrm{O}_{5}$ glasses. Phys. B Condens. Matter 2004, 353, 82-91. [CrossRef]

11. Al-Shahrani, A.; El-Desoky, M.M. Electrical transport studies in alkali iron phosphate glasses. J. Mater. Sci. Mater. Electron. 2006, 17, 43-49. [CrossRef]

12. Dutta, B.; Fahmy, N.A.; Pegg, I.L. Effect of mixing transition ions in glasses. II. The $\mathrm{P}_{2} \mathrm{O}_{5}-\mathrm{Fe}_{2} \mathrm{O}_{3}-\mathrm{MnO}$ system. J. Non-Cryst. Solids 2005, 351, 2552-2561. [CrossRef]

13. Al-Shahrani, A.; Al-Hajry, A.; El-Desoky, M. Electrical relaxation in mixed lithium and sodium iron phosphate glasses. Phys. B Condens. Matter 2005, 364, 248-254. [CrossRef]

14. Murawski, L. Electronic conductivity in $\mathrm{Na}_{2} \mathrm{O}-\mathrm{FeO}-\mathrm{P}_{2} \mathrm{O}_{5}$ glasses. Solid State Ionics 2003, 157, $293-298$. [CrossRef]

15. Moguš-Milanković, A.; Šantić, B.; Day, D.; Ray, C. Electrical conductivity in mixed-alkali iron phosphate glasses. J. Non-Cryst. Solids 2001, 283, 119-128. [CrossRef]

16. Moguš-Milanković, A.; Šantić, A.; Reis, S.; Furic, K.; Day, D. Mixed ion-polaron transport in $\mathrm{Na}_{2} \mathrm{O}-\mathrm{PbO}-\mathrm{Fe}_{2} \mathrm{O}_{3}-\mathrm{P}_{2} \mathrm{O}_{5}$ glasses. J. Non-Cryst. Solids 2004, 342, 97-109. [CrossRef]

17. Moguš-Milanković, A.; Šantić, A.; Karabulut, M.; Day, D. Study of electrical properties of $\mathrm{MoO}_{3}-\mathrm{Fe}_{2} \mathrm{O}_{3}-\mathrm{P}_{2} \mathrm{O}_{5}$ and $\mathrm{SrO}-\mathrm{Fe}_{2} \mathrm{O}_{3}-\mathrm{P}_{2} \mathrm{O}_{5}$ glasses by impedance spectroscopy. II. J. Non-Cryst. Solids 2003, 330, 128-141. [CrossRef]

18. Šantić, A.; Kim, C.; Day, D.; Moguš-Milanković, A. Electrical properties of $\mathrm{Cr}_{2} \mathrm{O}_{3}-\mathrm{Fe}_{2} \mathrm{O}_{3}-\mathrm{P}_{2} \mathrm{O}_{5}$ glasses. Part II. J. Non-Cryst. Solids 2010, 356, 2699-2703. [CrossRef]

19. Zielniok, D.; Cramer, C.; Eckert, H. Structure/property correlations in ion-conducting mixed-network former glasses: Solid-state NMR studies of the system $\mathrm{Na}_{2} \mathrm{O}-\mathrm{B}_{2} \mathrm{O}_{3}-\mathrm{P}_{2} \mathrm{O}_{5}$. Chem. Mater. 2007, 19, 3162-3170. [CrossRef]

20. Agarwal, A.; Seth, V.; Gahlot, P.; Khasa, S.; Arora, M.; Gupta, S. Study of electron paramagnetic resonance, optical transmission and dc conductivity of vanadyl doped $\mathrm{Bi}_{2} \mathrm{O}_{3} \cdot \mathrm{B}_{2} \mathrm{O}_{3} \cdot \mathrm{Li}_{2} \mathrm{O}$ glasses. J. Alloy. Compd. 2004, 377, 225-231. [CrossRef]

21. Muñoz, F.; Montagne, L.; Pascual, L.; Durán, A. Composition and structure dependence of the properties of lithium borophosphate glasses showing boron anomaly. J. Non-Cryst. Solids 2009, 355, 2571-2577. [CrossRef]

22. Kumar, S.; Rao, K. Lithium ion transport in germanophosphate glasses. Solid State Ionics 2004, 170, $191-199$. [CrossRef]

23. Prasad, P.S.S.; Rani, A.; Radhakrishna, S. Mixed glass former effect in AgI- $\mathrm{Ag}_{2} \mathrm{O}-\mathrm{V}_{2} \mathrm{O}_{5}-\mathrm{P}_{2} \mathrm{O}_{5}$ quaternary amorphous solid electrolytes. Mater. Chem. Phys. 1990, 25, 487-499. [CrossRef] 
24. Karabulut, M.; Yuce, B.; Bozdogan, O.; Ertap, H.; Mammadov, G. Effect of boron addition on the structure and properties of iron phosphate glasses. J. Non-Cryst. Solids 2011, 357, 1455-1462. [CrossRef]

25. Bingham, P.A.; Yang, G.; Hand, R.; Möbus, G. Boron environments and irradiation stability of iron borophosphate glasses analysed by EELS. Solid State Sci. 2008, 10, 1194-1199. [CrossRef]

26. Liao, Q.; Wang, F.; Chen, K.; Pan, S.; Zhu, H.; Lu, M.; Qin, J. FTIR spectra and properties of iron borophosphate glasses containing simulated nuclear wastes. J. Mol. Struct. 2015, 1092, 187-191. [CrossRef]

27. Moguš-Milanković, A.; Pavić, L.; Ertap, H.; Karabulut, M. Polaronic mobility in boron doped iron phosphate glasses: Influence of structural disorder on summerfield scaling. J. Am. Ceram. Soc. 2012, 95, 2007-2014. [CrossRef]

28. Räisänen, J. Handbook of Modern Ion Beam Analysis, 2nd ed.; Materials Research Society: Warrendale, PA, USA, 2009; pp. 147-173, and Appendices, Appendix 12 pp. 177-223.

29. Topić, N.; Radović, I.B.; Fazinić, S.; Skoko, Ž. Analysis of medieval and post-medieval glass finds from dubrovnik region (Croatia). Archaeometry 2016, 58, 574-592. [CrossRef]

30. Šantić, A.; Banhatti, R.D.; Pavić, L.; Ertap, H.; Yüksek, M.; Karabulut, M.; Moguš-Milanković, A. Polaronic transport in iron phosphate glasses containing $\mathrm{HfO}_{2}$ and $\mathrm{CeO}_{2}$. Phys. Chem. Chem. Phys. 2017, 19, 3999-4009. [CrossRef]

31. El-Desoky, M.; Kashif, I. Electrical conductivity in mixed calcium and barium iron phosphate glasses. Phys. Status Solidi A 2002, 194, 89-105. [CrossRef]

32. Al-Hajry, A.; Tashtoush, N.; El-Desoky, M. Characterization and transport properties of semiconducting $\mathrm{Fe}_{2} \mathrm{O}_{3}-\mathrm{Bi}_{2} \mathrm{O}_{3}-\mathrm{Na}_{2} \mathrm{~B}_{4} \mathrm{O}_{7}$ glasses. Phys. B Condens. Matter 2005, 368, 51-57. [CrossRef]

33. Al-Assiri, M.S.; Salem, S.; El-Desoky, M.M. Effect of iron doping on the characterization and transport properties of calcium phosphate glassy semiconductors. J. Phys. Chem. Solids 2006, 67, 1873-1881. [CrossRef]

34. Summerfield, S. Universal low-frequency behaviour in the a.c. hopping conductivity of disordered systems. Philos. Mag. B 1985, 52, 9-22. [CrossRef]

35. Summerfield, S.; Butcher, P. Universal behaviour of AC hopping conductivity in disordered systems. J. Non-Cryst. Solids 1985, 77, 135-138. [CrossRef]

36. Sklepić, K.; Banhatti, R.D.; Tricot, G.; Mosner, P.; Koudelka, L.; Moguš-Milanković, A. Insights from local network structures and localized diffusion on the ease of lithium ion transport in two mixed glass-former systems. J. Phys. Chem. C 2017, 121, 17641-17657. [CrossRef]

37. Šantić, A.; Nikolić, J.; Pavić, L.; Banhatti, R.D.; Mosner, P.; Koudelka, L.; Moguš-Milanković, A. Scaling features of conductivity spectra reveal complexities in ionic, polaronic and mixed ionic-polaronic conduction in phosphate glasses. Acta Mater. 2019, 175, 46-54. [CrossRef]

38. Roling, B.; Happe, A.; Funke, K.; Ingram, M.D. Carrier concentrations and relaxation spectroscopy: New information from scaling properties of conductivity spectra in ionically conducting glasses. Phys. Rev. Lett. 1997, 78, 2160-2163. [CrossRef]

39. Roling, B. Scaling properties of the conductivity spectra of glasses and supercooled melts. Solid State Ionics 1998, 105, 185-193. [CrossRef]

40. Sidebottom, D.L. Universal approach for scaling the ac conductivity in ionic glasses. Phys. Rev. Lett. 1999, 82, 3653-3656. [CrossRef]

41. Sidebottom, D.L.; Roling, B.; Funke, K. Ionic conduction in solids: Comparing conductivity and modulus representations with regard to scaling properties. Phys. Rev. B 2000, 63, 024301. [CrossRef]

42. Jonscher, A.K. Dielectric relaxation in solids. J. Phys. D Appl. Phys. 1999, 32, R57-R70. [CrossRef]

43. Banhatti, R.D.; Cramer, C.; Zielniok, D.; Robertson, A.H.J.; Ingram, M.D. Insights into ion-network interactions and ion transport in glass. Zeitschrift für Physikalische Chemie 2009, 223, 1201-1215. [CrossRef]

44. Bogomolov, V.N.; Mirlin, D.N. Optical absorption by polarons in rutile $\left(\mathrm{TiO}_{2}\right)$ single crystals. Phys. Status Solidi B 1968, 27, 443-453. [CrossRef]

45. Schrøder, T.B.; Dyre, J.C. Scaling and universality of ac conduction in disordered solids. Phys. Rev. Lett. 2000, 84, 310-313. [CrossRef]

(C) 2020 by the authors. Licensee MDPI, Basel, Switzerland. This article is an open access article distributed under the terms and conditions of the Creative Commons Attribution (CC BY) license (http://creativecommons.org/licenses/by/4.0/). 